\title{
Deconstructing leisure time and workload: case of women bean producers in Kenya
}

\author{
Eileen Bogweh Nchanji ${ }^{*} \mathbb{0}$, Mercy Mutua', Collins Odhiambo², Yvonne Kiki Nchanji ${ }^{3}$ and David Karanja4
}

\begin{abstract}
Background: The notion of leisure became pronounced more than 20 years ago when women who worked on or out of the farm came home to a "second shift," which entailed domestic work and childcare. This gap continues today not only between men and women but also among women and men. Women's challenges in terms of their leisure arise out of or are shaped by social norms and different life contexts.

Method: The Women's Empowerment in Agriculture Index (WEAI) was conducted to understand women's empowerment and disempowerment status in agricultural activities in five counties in Kenya in 2017. In 2019, focus group discussions were carried out in two of the five counties to understand how men and women farmers define leisure and assess the leisure gap and its effect on women's farm and household activities. We were also interested in understanding how men's and women's workload affects leisure and other productive economic activities, resulting in empowerment and how women's unpaid work contributes to income poverty.

Result: The WEAl showed that $28 \%$ of disempowerment (5DE) in women farmers is due to lack of time for leisure activities and $18 \%$ from being overworked. This means that the time indicator accounts for $46 \%$ of disempowerment in Kenyan women bean farmers. Men in Bomet and Narok spent more time than women in raising large livestock and leisure. Women in Bomet spent more time than men in cooking and domestic work (fetching water and collecting fuelwood), while men in Bomet spent more time than women in managing their businesses.

Conclusion: Work overload is a constraining factor to women's empowerment in bean production and agricultural productivity. What is considered leisure for men and women is embedded in society's social fabrics, and it is contextual. This paper highlights instances where leisure provides a way for women to embody and/or resist the discourses of gender roles in the bean value chain and households to enhance food security and health.
\end{abstract}

Keywords: Leisure, Workload, Gender, Deconstruction, Bean farming, Time use

\section{Introduction}

Individuals have always pursued activities that prompt their creative capacity by relaxing and increasing their knowledge or participation in other life obligations, and community engagements that require less human efforts [1]. Thus, playing, resting, and other forms of entertainment have been associated with leisure as a part of life, bringing fulfillment to human beings. Men have been

*Correspondence: e.nchanji@cgiar.org

${ }^{1}$ International Center for Tropical Agriculture, Nairobi, Kenya

Full list of author information is available at the end of the article observed to spend more time on leisure than women. For example, Ref. [2] found that men spend five hours more per week on leisure on average compared to their female counterparts. Ref. [3] in his study, $72 \%$ of women reported having at least half an hour of free time each day for leisure. Women are considered caregivers and are often preparing meals, taking care of children, and incharge of household cleaning and laundry, among other household chores compared to their male counterparts.

Women's work has always been considered tedious, repetitive, and time consuming, thus associated with the concept of "time poverty," as indicated in the poverty

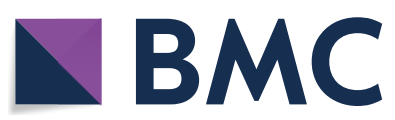

(c) The Author(s) 2021. This article is licensed under a Creative Commons Attribution 4.0 International License, which permits use, sharing, adaptation, distribution and reproduction in any medium or format, as long as you give appropriate credit to the original author(s) and the source, provide a link to the Creative Commons licence, and indicate if changes were made. The images or other third party material in this article are included in the article's Creative Commons licence, unless indicated otherwise in a credit line to the material. If material is not included in the article's Creative Commons licence and your intended use is not permitted by statutory regulation or exceeds the permitted use, you will need to obtain permission directly from the copyright holder. To view a copy of this licence, visit http://creativeco mmons.org/licenses/by/4.0/. The Creative Commons Public Domain Dedication waiver (http://creativecommons.org/publicdomain/ zero/1.0/) applies to the data made available in this article, unless otherwise stated in a credit line to the data. 
literature [4]. According to [5], "what particularly characterizes women's roles in contrast to those of men, is that they must carry out their roles simultaneously, not sequentially. This is evident not only in the extent of women's work burden and their very long working hours but also in the harsh choices and trade-offs they inevitably have to make because of the simultaneous competing claims on their time." Other factors that influence time use patterns between and among men and women are household composition, access to economic services, access to fuel and water, and most pressing social and cultural norms [5].

Time poverty has important implications for household food security and the well-being of the whole family. Women spend most of their time caring for the family, producing mostly unpaid food, and in very few cases carry out small informal businesses inhibiting their ability to be involved in more economical/productive activities [6]. The assumption that women would carry out more productive economic activities might not always be the case if they have more leisure time.

A study carried out by [7] in Nepal showed that saved time was not always visible, as women carried out additional domestic work during their free time. Similarly, Ref. [8] carried out a study in Vietnam that showed that when time spent on hand weeding was reduced, women spent more time on reproductive, income-generating, and community activities. A survey by Ref. [9] showed that few women respondents considered "more free time" a life priority, even though they valued leisure time.

Leisure is defined in Ref. [9] as a period free of timeconsuming duties or responsibilities. Leisure activities are sometimes considered relaxed family interaction with their social networks in church, the community, or home. Such activities are defined by and even among men and women differently depending on their socio-cultural and economic context. For example, in Egypt, social interaction is not considered free time by women, while in Uttar Pradesh, India, free time is considered leisure, as long as the woman is stationary, even if she is mending clothes [9].

Thus, activities considered as leisure differ with geographic location and cultural settings. Women's burden has been exacerbated by culturally underpinned expectations, such as women's submission [10]. These societal and institutionalized norms are often used to model women's behavior around men and how they need to appear. This often extends to leisure activities, such as sports. Women performing in sports activities that require energy are often perceived as masculine.

Instances where such cultural aspects have been observed to exploit women have been reported. In Kenya, a study in the informal urban slum noted that women spent $11.1 \mathrm{~h}$ per day for any care and domestic work compared to $2.9 \mathrm{~h}$ per day for men [11]. This was attributed to social norms as $44 \%$ of women respondents stated that they knew men who were shamed and mocked for carrying out unpaid care and domestic work (UCDW). In addition, $45 \%, 62 \%$, and $71 \%$ of men have never seen another man prepare a meal, clean the house, and wash clothes, respectively. Lastly, $73 \%$ of women were satisfied with how the tasks were shared as they considered UCDW a woman's activity.

Reference [12] found that men's labor force participation was higher than that of women's, but when women's non-market work activities were counted, the picture was different. Also, Ref. [13] discovered that males benefited more from creating skilled, wellpaying jobs than their female counterparts, who often supported men through unpaid work at home and on the farm. This conclusion was arrived at by simulating the employment effects of investing in priority sectors identified in Vision 2030 using the 2003 Kenya Social Accounting Matrix. Women spent more time than men on unpaid work, and men spend double their time in paid work than women (10.5 vs. $5.3 \mathrm{~h}$ per day, respectively). Women and men spent almost equal time on leisure and sleep (11.7 vs. $12.0 \mathrm{~h}$, respectively) as described in Ref. [11]. Thus, women lack the opportunity to engage in paid work. Even though women play a significant role in agriculture and supply about $65 \%$ of the labor force, their work is still considered invisible as most of it is unpaid.

So, time poverty may reinforce income poverty, adversely affecting household well-being, especially because women and children have to make trade-offs between market-oriented and household activities [4, 14]. These trade-offs result from competing claims on women's time, which may result in long-run impacts, like overall food insecurity of the household [15].

This paper seeks to understand how men and women define leisure time and how leisure myths can be deconstructed. We also estimate the opportunity cost of women's unpaid labor and assess whether it contributes to income poverty.

We developed a conceptual framework that links agricultural practices with time use patterns to understand the effect of workload/leisure on food security. With a mixed-methods approach and new datasets, this study informs future research and gender empowerment policy interventions to improve time allocation within households hoping that outcomes, such as food security and nutrition, will be positively influenced. The dataset used for this analysis is from a primary household survey in five counties (Bomet, Narok, Machakos, Homabay, and Makueni) in Kenya in 2017 and qualitative data 
(4 sex-disaggregated focus group discussion) from two counties (Bomet and Narok) out of the five counties in 2019.

\section{Conceptual framework}

According to the social role theory by Refs. [16-18], men and women have been assigned roles and responsibilities as a result of biological, psychological differences, and cultural norms. For example, men's physical strength and size historically led them to pursue warfare activities, giving them status, power, and wealth than women. Once men's behavior became dominant, women were expected to accommodate that behavior and become more subordinate. Also, women's biological capacity to bear children and feed them resulted in nurturance and relationship skills. Over time, men and women have adapted to their assigned roles prescribed by culture. This resulted in a gendered division of labor permeating our societies today, where men are considered the primary breadwinners and women homemakers.

As men and women perform their roles, they develop skills to help them succeed in these roles to meet societal expectations, as people who do not conform to gender roles risk being socially rejected. Although gendered roles seem suited to biological differences between men and women, there is a power dimension associated with these roles. Women are still more economically dependent due to limited access to resources, opportunities, training, and bargaining power in the household. Men construct these prescribed roles and responsibilities in patriarchal societies and so defines women's access to leisure.

For this study, leisure is considered a pleasurable activity, different from one's routine activity or what is considered work. It could or not be productive, but it is not attached to one's social role or responsibilities. Thus, what is considered leisure for men and women is embedded in their different social fabrics. Leisure provides a way for women or men to embody and/or resist the discourses of gender roles. This paper, therefore, shows how women embrace and sometimes resist their roles through different covert strategies.

\section{Study area and methodology Study area}

The Bomet county lies between latitude $0^{\circ} 29^{\prime}$ and $1^{\circ} 03^{\prime}$ South and longitudes $35^{\circ}$ and $35^{\circ} 35^{\prime}$ East in the Rift Valley (Fig. 1). Four counties border it: Kericjo to the north, Nyamira to the west, Narok to the south, and Nakuru to the northeast. The projected population of the county in 2018 was 922, 888 inhabitants with more than half being women. Agriculture is the main activity in this county, with farmers involved in dairy, tea, coffee, bean,

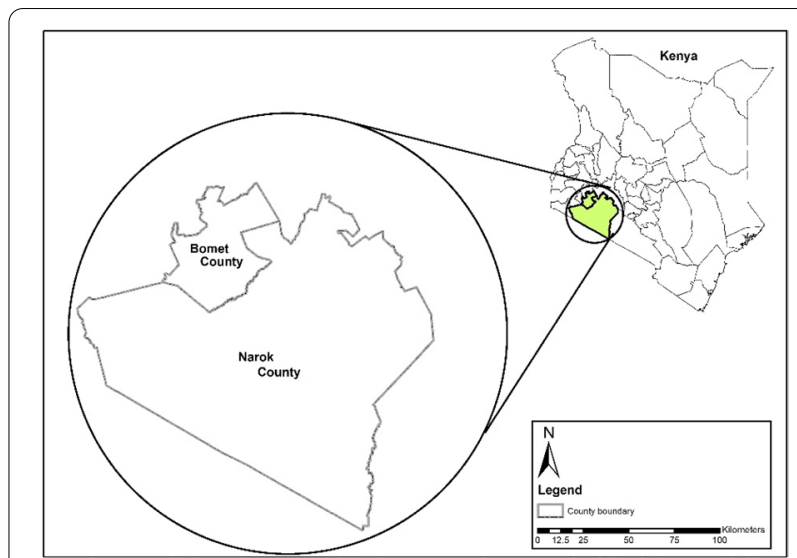

Fig. 1 Map of two study areas, Narok and Bomet

sorghum, Irish potato, millet, cabbage, and onion production for local and national markets. The Kalenjin are the leading ethnic group in this county, and as per their culture, women do not own land nor make decisions on-farm and in the households; if they have to make any decision, their spouses must be consulted [19].

Narok county lies between latitudes $0^{\circ} 50^{\prime}$ and $1^{\circ} 50^{\prime}$ South and longitudes $35^{\circ} 28^{\prime}$ and $36^{\circ} 25^{\prime}$ East and is located on the South Western side of the country along the border of Kenya and Tanzania in Fig. 1. Ref. [20] pointed out that Narok is commonly referred to as the breadbasket of the country due to its relatively high production of wheat, barley, livestock, Irish potato, and bean. About two-thirds of Narok county is classified as semi-arid. From the 1990s to 2000, it experienced extreme climatic shocks from droughts to floods [21]. Narok is occupied mainly by the Maasai ethnic group. In the Maasai culture, women perform all household chores, including agricultural and livestock activities. For example, they construct huts, fetch water, feed, and milk livestock, gather fuelwood, cook, and care for the children and elderly.

\section{Data collection and sampling}

The women empowerment in agriculture index (WEAI) tool was used to collect data from men and women bean farmers in five counties (Bomet, Narok, Machakos, Homabay, and Makueni) in Kenya. Data were collected on various indicators of empowerment, which included an array of issues such as input in production decisions, and autonomy in production decisions, ownership of assets, purchase or sale or transfer of assets, access to and decisions on credit, control over the use of income, group membership, workload, and leisure. The analysis was carried out using the WEAI to understand how such factors contributed to women's empowerment 
or disempowerment in bean farming. The WEAI data were complemented with qualitative data collected in Narok and Bomet in March 2019. The two counties were purposively selected because of their nearness and their different cultural and livelihood practices within the communities (pastoralism vs. agricultural). Bomet is an agricultural area with good rains and a colder climate. Narok, on the other hand, has a dry climate, and the community practice pastoralism. Qualitative data were collected via the use of four sex-disaggregated focus group discussions (FGDs). FGD consisted of a minimum of 8 members (at least four women, three men, and a youth of any sex), as shown in Fig. 2.

A total of 35 participants formed part of the FGDs. Prior to the FGDs, a semi-structured questionnaire was administered in the presence of both men and women to collect socio-demographic information. Later on, women and men were separated to answer issues related to time use specifically. Men and women groups were later merged to discuss the differences in time use between genders and agree on points of action to remedy the negative findings. This validated and triangulated the data collected from the different groups. During the exercise, moderation was important to make sure men do not dominate the discussion and women stayed quiet due to cultural expectations.

\section{Data analysis}

The WEAI is a weighted index composed of two subindexes: The Five Domains Empowerment (5DE) Index and the Gender Parity Index (GPI). The 5DE accounts for $90 \%$, while the GPI accounts for $10 \%$ of the WEAI; thus, the WEAI computation formula is $0.9 * 5 \mathrm{DE}+0.1 * \mathrm{GPI}$. The 5DE measures an individual's extent of decisionmaking power in 5 domains: production, resource control, income, leadership, and time use. The GPI, on the other hand, is a measure of a woman's empowerment

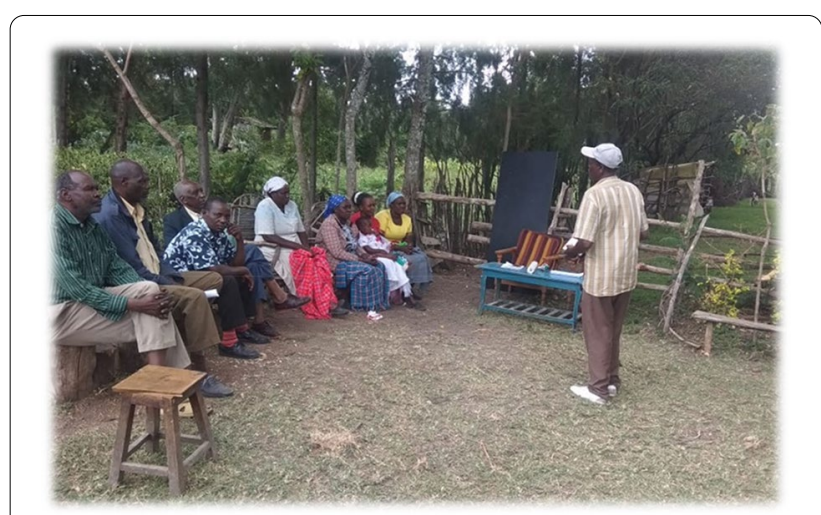

Fig. 2 Focus group discussion in Narok County, Kenya relative to the male decision-maker in the household, hence a measure of intra-household gender (in)equality [22]. While the 5DE uses data from women and men in households that can be either dual (female and male) headed, the GPI can only be computed for women in households with dual decision-makers (both men and women).

Each of the five domains is composed of one to three indicators totaling ten indicators in the 5DE. The production domain measures an individual's empowerment on decision-making regarding agricultural production and is composed of two indicators: input in production decisions and autonomy in production decisions. The resource domain comprises three indicators relating to ownership of productive assets; acquisition, use, and disposal of assets; and access to and credit decisions. The income domain refers to control overuse of income in the household, while the leadership domain is composed of two indicators: membership in economic and social groups and ability to speak in public.

The time domain has two indicators, the first being an individual's satisfaction with the available time for leisure activities and the second being workload, including time spent in productive activities and domestic tasks. Each of the five domains accounts for an equal weight of $20 \%$ in the 5DE sub-index. The ten indicators are allocated a weight based on the number of indicators in the domain in which they respectively fall, as shown in Table 1.

An adequacy criterion is defined to determine if an individual is empowered or not in each indicator (Table 2).

In the computation of the 5DE and WEAI, each respondent is assigned a binary score depicting adequacy in each of the indicators based on the criteria. The weights of the indicators where one is adequate are then summed up to generate a score (with values ranging from 0 to 1 ), which is the 5DE. For example, one is considered empowered (in terms of 5DE) if they are adequate in at least four of the five domains or if their sum of the weighted score is at least $80 \%$ [23].

Also, the data collected from the FGD and semistructured checklist were analyzed thematically. Content Analysis was generally applied to derive the most occurring phrases. First, the comments and answers were transcribed from all the focus groups. The comments were re-arranged to obtain answers for each interview protocol question. For each question, the frequency of occurrence and theme coming out was noted, taking into account the same basic ideas that occur in multiple questions. Themes were used as wrappers around several distinct statements and discussions underpinned by literature. The "why?" behind the themes was deducted to explain the outcomes of the study. 
Table 1 The 5 DE indicators and their weights

\begin{tabular}{|c|c|c|c|}
\hline Domain & Indicator & Indicator weight & Domain weight \\
\hline \multirow[t]{2}{*}{ Production } & Input in production decisions & 0.100 & 0.200 \\
\hline & Autonomy in production decisions & 0.100 & \\
\hline \multirow[t]{3}{*}{ Resources } & Ownership of assets & 0.067 & 0.200 \\
\hline & Purchase/sale/transfer of assets & 0.067 & \\
\hline & Access to and decisions on credit & 0.067 & \\
\hline Income & Control over use of income & 0.200 & 0.200 \\
\hline \multirow[t]{2}{*}{ Leadership } & Group member & 0.100 & 0.200 \\
\hline & Speaking in public & 0.100 & \\
\hline \multirow[t]{2}{*}{ Time } & Workload & 0.100 & 0.200 \\
\hline & Leisure & 0.100 & \\
\hline
\end{tabular}

Table 2 Indicator adequacy criteria. Source Adapted from WEAI-DATAPREP'; do-file by Ref. [23]

\begin{tabular}{|c|c|}
\hline Indicator & Adequacy criteria \\
\hline & An individual is considered adequate/ empowered if \\
\hline Input in production decisions & (S)he participates (or feels they can give Input) in at least two types of production decisions \\
\hline Autonomy in production decisions & $\begin{array}{l}\text { Their actions with regard to agricultural production are motivated by their values rather than by fear of disapproval } \\
\text { or coercion }\end{array}$ \\
\hline Ownership of assets & They own (solely or jointly with others) at least one major asset or two minor assets \\
\hline Purchase/sale/transfer of assets & They have at least one type of right to buy, sell, or transfer assets within the household \\
\hline Access to and decisions on credit & They have access to credit and can make at least one decision regarding borrowing or use of credit \\
\hline Control over the use of income & $\begin{array}{l}\text { One has Input on decisions regarding the use of income that (s)he participated in earning, provided such Input is } \\
\text { not on minor household purchases }\end{array}$ \\
\hline Group member & They have active membership in at least one social or economic group \\
\hline Workload & They did not work for more than $10.5 \mathrm{~h}$ in the previous $24 \mathrm{~h}$ \\
\hline Leisure & $\begin{array}{l}\text { They do not express any level of dissatisfaction with their available time for leisure activities, i.e., scored } \geq 5 \text { on a } \\
\text { scale of } 1-10\end{array}$ \\
\hline
\end{tabular}

This excludes minor assets like chicken, non-mechanized farm equipment, and small consumer durables

\section{Results and discussion}

\section{Socio-demographics of farmers}

The socio-demographics FGD we had in Narok and Bomet showed that the proportion of women to men was $43 \%$ and $57 \%$, respectively. Although more women were invited, attendance was dominated by men because of cultural reasons, like mobility; i.e., men preferred traveling long distances while women were expected to stay home and take care of the family. Moreover, the FGD's were held during the drought period when women were expected to fetch wood and water for their households. Hence, the proportion of men who participated in the FDG were higher than that of women. In cases where women's attendance was $\geq 50 \%$, meetings were held close to their homesteads. About $45 \%$ of the respondents were young men and women.

Most households are made up of children less than 15 years and youths, which are defined as (< or 35 years) as per the African Union and Kenya Constitution of 2010, respectively (Fig. 3).

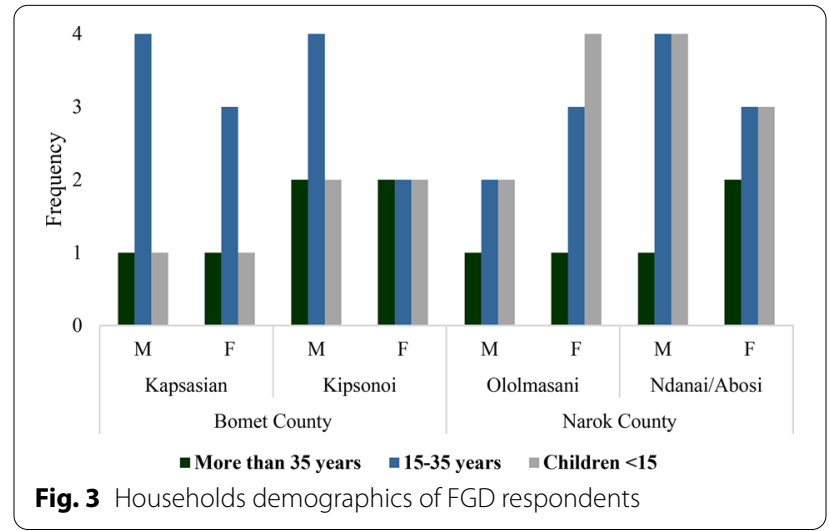

Leisure activities

The frequency of thematic words or occurrence and commonality of certain words was used to rank the statements given in Table 3. When it came to leisure activities, most men spent a significant amount of time in the 
Table 3 Summary of leisure activities

\begin{tabular}{|c|c|c|c|}
\hline \multicolumn{2}{|l|}{ Women } & \multicolumn{2}{|l|}{ Men } \\
\hline Frequent leisure activities & Rank & Frequent leisure activities & Rank \\
\hline Visiting the old, sick neighbors & 1 & $\begin{array}{l}\text { Visiting town places with agemates to talk politics and get } \\
\text { updates on developmental issues }\end{array}$ & 1 \\
\hline Reading the Bible, singing, and praying & 2 & Watching football and movies & 2 \\
\hline Playing with children & 3 & Betting (sportpesa) and social media use & 3 \\
\hline Listening to radio & 4 & Visiting the sick, friends, and neighbors & 4 \\
\hline Collecting wild fruit & 5 & Patrolling compound and looking at home projects & 5 \\
\hline Interacting with family & 6 & Interacting with family & 6 \\
\hline Relaxing under shade & 7 & Sleeping & 7 \\
\hline
\end{tabular}

Ranks are based on frequencies of leisure activities

Table 4 Participation in community activities

\begin{tabular}{lll}
\hline Activity & $\begin{array}{l}\text { Who participated } \\
\text { most }\end{array}$ & Rank \\
\hline Religious activities & Women & 1 \\
Burials & Men & 2 \\
Merry-go round/table banking & Women & 3 \\
Community Harambee/fundraising & Both & 4 \\
School meetings & Women & 5 \\
Wedding & Women & 6 \\
Community meetings and gatherings & Men & 7 \\
\hline
\end{tabular}

Harambee is a Swahili word that means "pulling together"

main local markets and centers to interact with their peers. During which, they talk about politics, watch football, and gamble. In contrast, women spend more time visiting the sick, elderly, and neighbors. The same scenario was also observed by Ref. [24] in their study in Tanzania and Kenya. Both genders ranked interacting or spending time together as one of the last activities. While men considered leisure time as free time spent sleeping, playing sports games, chatting with friends, and checking home projects, women considered leisure as time spent with the sick, church members, and the children and elderly. Women's leisure time was spent carrying out care activities, unlike men, in contrast with Ref. [9], where leisure is a period free of time-consuming duties or responsibilities.

Religion was considered the highly ranking community activity for women shown in Table 4 . Religion was a very important part of daily life and formed part of women's leisure time. Most women viewed religion as a leisure time activity rather than a prescribed role or work because to them, "it was the only time they did what gave them joy and happiness."

Some women considered involvement in religious activities as some kind of community expectations. As such, those who never practiced it were looked at "differently." Others differed and said, "It is what the community expects us to do, but it is not a leisure nor community activity. It is a church activity where everybody bonds."

The study explored whether women used leisure as a resistance instrument to socio-cultural taboos, especially deeply rooted ones. Women used most of their leisure time $(46 \%)$ to visit neighbors and friends and participate in religious activities as shown in Fig. 4. During religious activities, women discussed family issues and learned how to solve them from each other. The church has also become a safe space where women and girls are trained on harmful traditional practices and where alternative masculinities are suggested [25]. Discussing was considered a therapeutic exercise by most women. By so doing, they got solutions via advice from friends and religious leaders to some of their problems. Women visited neighbors and friends to start a "chama"-women-only table banking. Through such groups, women said they were at liberty to borrow among themselves and start new businesses that would give them more rest from household chores, as they could afford hired help and could continually invest in more productive activities. However, the study could not establish whether this kind of leisure activity would lead to other forms of resistance. It is worth noting that women viewed submission as a culturally intricate idea; as such, discussing "resistance" was not easy. Men had more leisure time (64\%) compared to women. Men's definition of leisure has been constructed and embedded in the social fabrics of rural life. Men are expected to spend more time out in the market square, gamble, and eat "Nyama Choma," and women accept it as a part of life.

\section{Time use}

As part of the WEAI tool, a time log of all activities respondents was involved in was administered to both men and women respondents based on a $24-\mathrm{h}$ recall. 


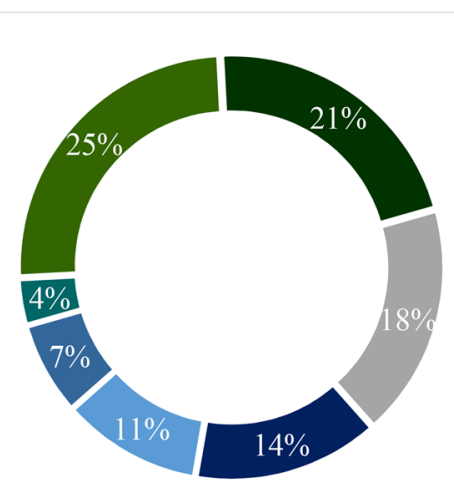

Male's Activities Ranked by Frequency

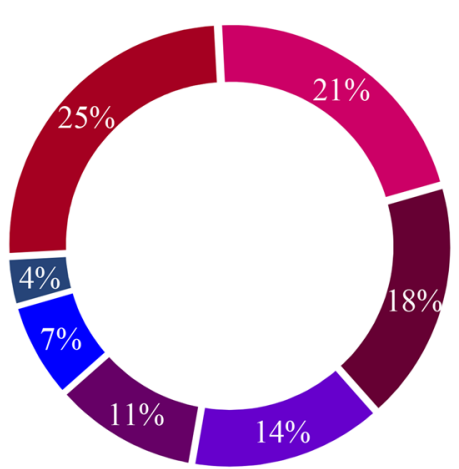

- Visits to friends, neighbors

- Religious activities

- Play with children

- Listening to radio

- Interacting with

family

- Relaxing under

shade

- Collecting wild fruit

Fig. 4 Men and women leisure activity ranked in the frequency of occurrence, respectively

Table 5 presents the average number of hours spent in each activity.

In Bomet County, men on average spend $7.75 \mathrm{~h}$, while women spend $5.25 \mathrm{~h}$ on employment activities outside their farms. This $2.5 \mathrm{~h}$ ' difference is significant at the $10 \%$ level. Similarly, men spend more time taking care of livestock animals with a difference of $1.71 \mathrm{~h}$ per day in Bomet and $1.57 \mathrm{~h}$ in Narok compared to women, with differences being significant at $1 \%$ level. This may be because both counties are considered agro-pastoralist. Keeping livestock in these counties contributes an important part to household incomes, which in most cases are controlled by men. Women, on the other hand, outdo men with regard to the time they spend cooking (1.72 h' difference

Table 5 Average number of hours spent in activity per day by men and women farmers

\begin{tabular}{|c|c|c|c|c|c|c|}
\hline \multirow[t]{2}{*}{ Activity } & \multicolumn{3}{|c|}{ Bomet } & \multicolumn{3}{|l|}{ Narok } \\
\hline & Male & Female & Diff & Male & Female & Diff \\
\hline Sleeping and resting & 10.26 & 9.70 & 0.56 & 10.13 & 9.97 & 0.16 \\
\hline Eating and drinking & 2.00 & 1.86 & 0.14 & 1.80 & 1.73 & 0.07 \\
\hline Personal care & 0.65 & 0.65 & 0.01 & 0.77 & 0.67 & 0.11 \\
\hline School (including homework) & & & 0.00 & 3.17 & & 3.17 \\
\hline Work as employed & 7.75 & 5.25 & $2.5^{*}$ & 7.10 & & 7.1 \\
\hline Own business work & 7.25 & 5.67 & 1.58 & 5.09 & 4.15 & 0.94 \\
\hline Staple grain farming & 3.97 & 3.65 & 0.32 & 2.88 & 3.10 & -0.22 \\
\hline Horticultural (gardens) or high value crop farming & 0.75 & 1.82 & -1.07 & 1.00 & 1.86 & -0.86 \\
\hline Large livestock raising (cattle, buffaloes) & 3.04 & 1.33 & $1.71^{* * *}$ & 4.03 & 2.46 & $1.57^{* * *}$ \\
\hline Small livestock raising (sheep, goats, pigs) & 0.63 & 0.60 & 0.03 & 2.00 & 1.42 & 0.58 \\
\hline Poultry and other small animals raising (chickens, ducks, and turkeys) & 1.00 & 0.90 & 0.10 & & 1.00 & -1 \\
\hline Commuting (to/from work or school) & 1.50 & 1.00 & 0.50 & 1.75 & 1.00 & 0.75 \\
\hline Shopping/getting service (including health services) & 1.33 & 0.67 & $0.66^{* *}$ & 2.50 & 2.00 & 0.5 \\
\hline Cooking & 0.50 & 2.22 & $-1.72^{* * *}$ & 1.50 & 2.25 & -0.75 \\
\hline Domestic work (including fetching water and collecting fuel) & 0.75 & 2.34 & $-1.59^{* * *}$ & 2.00 & 2.96 & -0.96 \\
\hline Caring for children & & 1.20 & -1.20 & 1.00 & 1.22 & -0.22 \\
\hline Caring for adults (sick and elderly) & 4.00 & 12.50 & -8.50 & 1.50 & & 1.5 \\
\hline Traveling (not for work or school) & 1.55 & 1.00 & 0.55 & 1.63 & 1.37 & 0.26 \\
\hline Exercising & 0.50 & & 0.50 & 0.50 & & 0.5 \\
\hline Social activities and hobbies & 2.91 & 1.70 & $1.21^{* * *}$ & 2.52 & 0.91 & $1.61^{* * *}$ \\
\hline Religious activities & 2.00 & 2.41 & -0.41 & 0.63 & 0.75 & -0.13 \\
\hline
\end{tabular}

$*^{* *}$, and ${ }^{* * *}$ significant at $10 \%, 5 \%$, and $1 \%$, respectively 
significant at $1 \%$ level) and other domestic chores, like cooking and fetching water and fuelwood (1.59 h' difference, $p<0.01)$. When it comes to social activities and hobbies, men in both counties spend significantly more time than women. In Bomet, men spend an average of $2.91 \mathrm{~h}$ while women spend $1.70 \mathrm{~h}$ on social activities and hobbies, with the difference being significant at $1 \%$ level. Similarly, Narok men spend an average of $2.52 \mathrm{~h}$, while women spend $0.91 \mathrm{~h}$ on hobbies and social activities. This information is complemented by a "thick description" below on how men and women spend their day from morning to night. The information below was gathered from the focus group discussions.

\section{a. Morning hours (6 a.m.-12 p.m.)}

The difference in time use was observed between men and women farmers. Women reported a routine duty to wake up, make breakfast, and prepare children for school between 6 and 7 a.m. After which, they embarked on intra-household chores, such as washing dishes, tidying up the house, and fetching water from the river. This took an average of two hours (7 a.m. to 9 a.m.), with some finishing earlier. Most women engaged in off-farm duties, especially off-farm labor supply and trading in milk. Those who stayed home looked for feeds for the animals and participated in on-farm farming until midday before breaking to prepare lunch for children in day schools. Men's activities took a different trajectory. Most reported waking up at 6 am then walking around to see how the animals fared. Some men woke up to listen to the radio as the wives prepared breakfast and children for school. The activity had a high frequency between 6 and 7 a.m. By 8 a.m., most men reported looking for feeds for the animals and tending to the areas with animal feeds, mostly Napier grass. According to the cultural requirement, there were reports of engaging in trade and related activities that men be the providers for the families. These activities peaked at around midday.

\section{b. Afternoon (12 p.m.-3 p.m.)}

At this point, women reported a high frequency of intrahousehold activities, especially preparing lunch for the family. Most men reported providing water and additional feeds to cattle for around $45 \mathrm{~min}$, then rested to listen to the news while lunch was getting ready. Some women reported extra household chores after lunch, mainly tidying the house and washing dishes. This was followed by 30 -min to 1 -h rest in the shade, a factor they considered leisure time.

$$
\text { c. Evening (3 p.m.-7 p.m.) }
$$

For most men, this marked the beginning of visiting the nearest town to catch up with the latest developments and politics. This activity was considered "healthy" and "appropriate" as it refreshed men. However, others indicated that it was the most appropriate time to graze the animals. They reported additional routine works for women, especially trade and on-farm activities, such as grazing cattle and participating in off-farm labor.

$$
\text { d. Night hours (7 p.m.-10 p.m.) }
$$

Most women reported intrahousehold chores and activities related to preparing food. Men reported relaxing and watching the news. This was associated with the cultural taboo that prohibits men from cooking as it would lead to a curse. Surprisingly, women tended to object to the proposal of men cooking as it would bring shame to them, for the community would mock them as not being good wives.

$$
\text { e. Midnight (11 p.m.-2 p.m.) }
$$

This time had little activities except that men provided security by walking around the house and making sure everything was fine.

To make sense of the data, we got men and women farmers together in one FGD to validate and triangulate the data from time use presented by the different genders. When that was done, we were able to generate Table 6.

Women spend more time carrying out domestic activities like household chores, cooking, and child care while men spend most of their time feeding, grazing the animals, and milking. While women had only two hours reserved for leisure, men had $6 \mathrm{~h}$ for leisure activities. While men spend more time in off-farm activities, women spend double that time on on-farm activities. These detailed time use corroborated with WEAI studies shown in Table 5 and other existing literature $[2,5,11$, 25].

\section{Bean value chain}

Men and women perform different roles in the bean value chain, shaped by culture and community expectations. We see more men or women carrying out most farm activities depending on the crop and socio-cultural context. In Kenya, common bean production and agriculture are dominated by women [26], and we see same scenario in Cameroon [27]. From focus group discussion, men select land to cultivate beans and other crops as highlighted by Ref. [28-30] in Uganda, Ethiopia, and Kenya, respectively. Men were also expected to prepare the land using oxen due to the strength required. 
Table 6 Social Activities Summarized within time range and frequency of occurrence

\begin{tabular}{|c|c|c|c|c|}
\hline \multirow[b]{2}{*}{ Activities } & \multicolumn{2}{|l|}{ Women } & \multicolumn{2}{|l|}{ Men } \\
\hline & $\begin{array}{l}\text { Average hours } \\
\text { spent }\end{array}$ & Time range & $\begin{array}{l}\text { Average hours } \\
\text { spent }\end{array}$ & Time range \\
\hline Household chores, cooking, and child care & 6 & 6 a.m.-9 a.m. and 6 p.m. -9 p.m. & 2 & 6 a.m.-8 a.m. \\
\hline Animal feeding/grazing and milking & 3 & 8 a.m.9 a.m. and 2 p.m.-3 p.m. & 6 & 7 a.m.-1 a.m. \\
\hline On-farm activities/labor & 3 & 9 a.m.-12 a.m. & 1 & 8 a.m.-9 a.m. \\
\hline Off-farm activities/labor & 2 & 3 p.m.-5 p.m. & 1 & 2 p.m.-3 p.m. \\
\hline Leisure/social activities & 2 & 1 p.m.-2 p.m. and 9 p.m.-10 p.m. & 6 & $\begin{array}{l}6 \text { a.m.-7 a.m., } \\
3 \text { p.m.-7 p.m., and } \\
9 \text { p.m.-10 p.m. }\end{array}$ \\
\hline Providing Security at Night & 0 & 10 p.m.-12 p.m. & 1 & 10 p.m.-11 p.m. \\
\hline Sleeping & 8 & 10 p.m.-6 a.m. & 7 & 11 p.m.-6 a.m. \\
\hline Total & $24 \mathrm{~h}$ & & $24 \mathrm{~h}$ & \\
\hline
\end{tabular}

During focus group discussions, men said, "women do not know how to use the ox-plow as it is heavy and needs muscles." Also, men are considered the household heads and, as such, had to make sure land was prepared for farming. Most women responded that "it is a man's duty to plow and prepare the land." The influencing theme that defined the role of men, in this case, was culture; identifying the man as the head of the household decides how labor is divided sometimes in consultation with his spouse. According to Ref. [31], "unlike the hoe or digging stick, the plow requires significant upper body strength, grip strength, and bursts of power, which are needed to either pull the plow or control the animal that pulls it," placing women at a disadvantage to men. A study by Ref. [32] showed that young farmers in Guai challenged the gender division of labor, giving examples of women who owned and used plows in their fields.

From the focus group discussion with women and men, seed selection was mentioned as a woman's activity. Men felt that women were more experienced in variety selection and understood better attributes, such as size, color, shape, and marketability of the variety. According to Ref. [29], in North-Eastern Ethiopia, women were involved in seed selection compared to South-Western Ethiopia, where both genders were involved in seed selection. The role of women in seed selection is also highlighted by [33] study in Rwanda, where women's involvement in seed selection led to their active participation in evaluating common bean breeding materials for release. In addition, Ref. [34] also showed that seed exchange is also along gender lines.

Planting and weeding also strongly came out as a woman's activity in both regions, a matter associated with women's availability at home most of the time. This ties in with [28] study on women and men participation in Uganda where women more than men took part in weeding and planting and [35] work in Tanzania and Kenya. However, this contrasts North Eastern and South Western Ethiopia, where men and women were both involved in planting and weeding [29]. Men considered off-farm jobs as the primary cause of not being involved in planting and weeding.

Harvesting was an activity for women and children, reflected in [28] study in Uganda. Interestingly, men were also involved in harvesting in Ethiopia [29]. Women uprooted the crops, and children offered support in its transportation. However, most men indicated they sometimes paid for the labor needed for threshing and sorting during the focus group discussion. Women cooked the bean as a cultural requirement. Men did not visit the kitchen as it would lead to a "curse." Also, if a man was found cooking, he was considered a fool [11].

Surprisingly, men dominated the marketing of beans, which was considered a woman's crop. During the focus group discussion, women said that since men were the head of the household, they had the sole right to sell beans mainly cultivated by women, in line with cultural constructions. Furthermore, most of the bean harvested is bartered as fees to schools, a phenomenon observed in rural areas across Eastern Africa [36]. The women said this benefitted the whole family; therefore, it did not bother them much. There were no significant differences in responses among the respondents in both Bomet and Narok.

\section{Access to water and fuel}

In both counties, fetching water and wood was a woman's activity. Women said they knew how to do it, and men who did this would be "cursed" or disrespected in the community. Again, strong cultural aspects played a significant role in shaping these two activities; an opinion also mirrored in Refs. [5] and [24]. The effect of walking 
long distances to fetch water and fuelwood has resulted in associated body pain and fatigue in boys, girls, and women. Cases of physical abuse have also been reported in Ref. [37]. Women said men were expected to buy food because they were "the owners of the money." Most youths were enfolded around their parents' activities.

\section{Farm tools and equipment}

Main farm implements included jembes, pangas, slashers, ox-plows, ax, fork jembes, filers, watering cans, wheelbarrows, planting lines, hand sprays, and hosepipes. Implements used in farms, mainly, jembes, were bought by women as they not only knew how to use it but used it more often than their male counterparts. Men owned heavy equipment, such as ox-plow and wheelbarrow. Masculinization of mechanized technologies in smallholder agriculture has been observed by Ref. [38]. Thus, a call for mechanization considers both women's and men's agricultural needs and roles in farming.

\section{Distance to social and economic amenities}

The question was asked based on average minutes from each individual's home, then averaged for the group. Since there were no outliers, the averages indicated better estimates of the distances the respondents were likely to cover to get to the nearest socio-economic amenity.

From Fig. 5, Ndanai/Abosi and Kapsasian are the farthest from the amenities. Amenities, like markets, input dealers, and health centers, which are vital for better pricing of agricultural produce and farmers' health, are furthest away from respondents. Mobility can overcome women and men farmers' constraints to access and utilize agricultural inputs (seed and fertilizer) that may improve both farm productivity and household incomes [39].

\section{Opportunity cost of household labor}

The study seeks to analyze time use by identifying and weighing the benefits and costs of particular activities for women and men, then looking into the trade-offs that maximize their utility. Women were separately asked to cost the labor they offered on-farm and do household chores against what they ought to have received had they used such labor in off-farm or business activities. To control for outliers, every woman within the group was asked if they had offered off-farm labor. The study procedure was based on an individual's participation in offfarm activities but not on their level of human capital as this would complicate the calculations.

The approach was a recall type where women were asked to recall when an activity they carried out in the house hindered their access to paid labor and the costs they would attach to that. This would make them recall the amount they charged for a day as it would be the best alternative they forgo when they offer that to their farms. Based on the principles of economic costing, three items were made clear: (1) direct payments of cash, (2) direct payments in kind, and (3) prevailing market rates. The answer ranged from charging 20 USD to 50 USD per man-day $(8 \mathrm{~h})$. Therefore, the average opportunity cost was USD 30 for $8 \mathrm{~h}$ a day. When adjusted for market rates

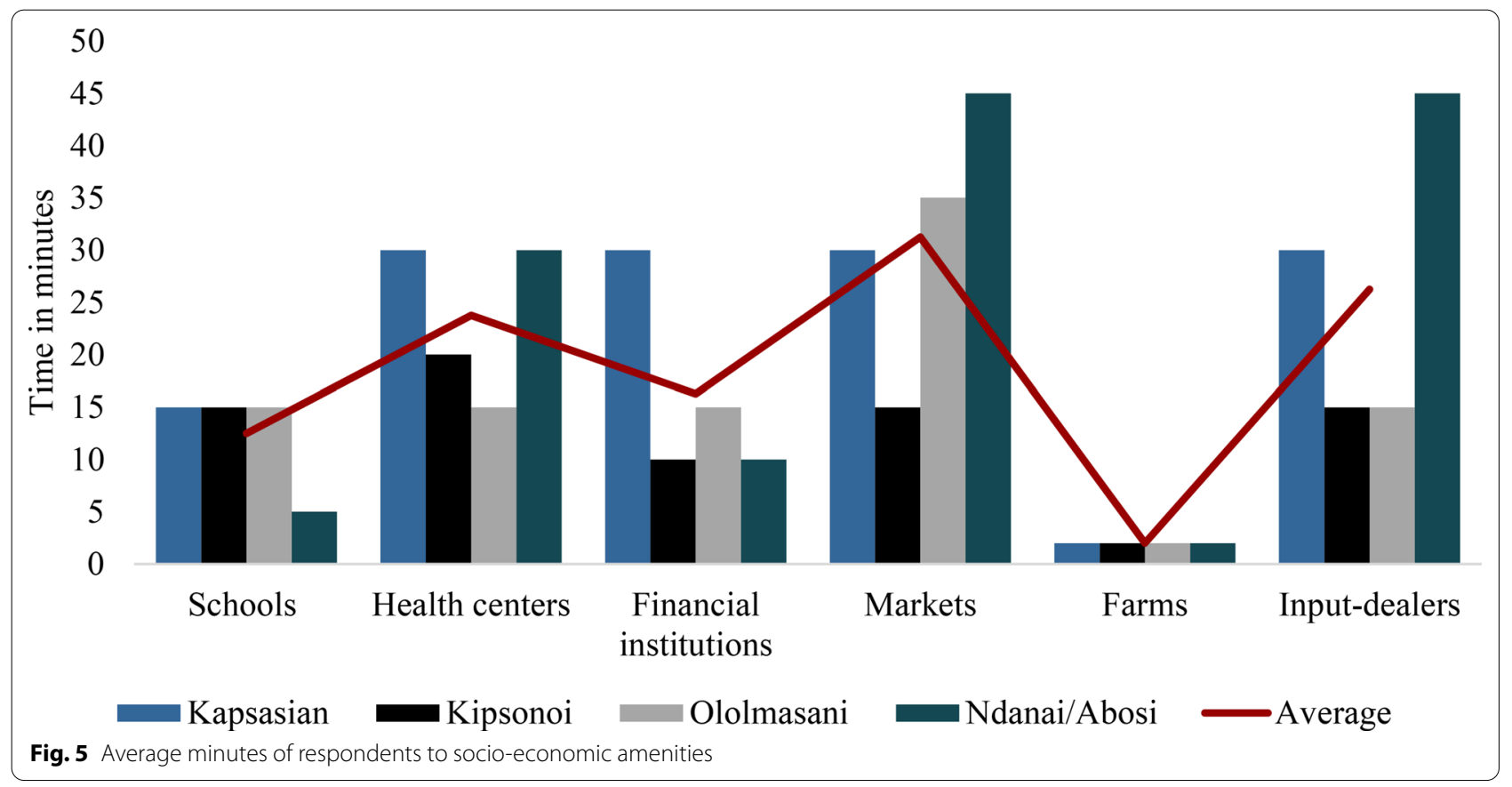


and based on the fact that this was a rural setting, the rate reflected what normal off-farm labor would bring in for an individual.

Men were not asked to cost their off-farm labor, and therefore, no direct comparison would be made with women's. Ref. [2] concluded that women were more likely than men to work overtime preparing and cooking meals while taking care of the children. Thus, every weekday time, $2.4 \mathrm{~min}$ per day loss resulted in a $10 \%$ increase in her opportunity costs. Valuing unpaid work has implications on contributions of unpaid work for women as it indicates the externalities to the economy in general that often remain unnoticed unless they are quantified in monetary terms. Thus, as Refs. $[4,14]$ pointed out, time poverty translates to income poverty with consequences on food and nutritional security in the household, elaborated in Ref. [24].

\section{Conclusion}

This study seeks to deconstruct time use among men and women, focusing on identifying constraining factors in women's leisure and general time use that could result in income poverty. Some of the insights from investigating general patterns of time allocation revealed a disproportionate gendered division of labor. Longer working hours negatively affected women's time spent preparing meals and, by default, the households' food security situation.

While men carried out a few activities, such as clearing the bushes and plowing, women dominate bean farm management, especially planting, weeding, harvesting, and threshing. Men were particularly concerned about the marketing of beans in cases where such would attract better returns. While income earned from agriculture is important for poor women's assets, men make most decisions from such income. Thus, income managed by men may exacerbate asset poverty status for women farmers in developing countries. When men control money accrued, most of it goes to leisure activities than the household.

Women also use time meant for their leisure (spend in the church) to reduce their exposure to harmful traditional practices and generate finance (during merry go rounds) to invest in small businesses to better their families' food security.

This study contributes to the women empowerment literature and policy by fronting women empowerment as a crucial element to derive culturally distinct and acceptable solutions while engaging men actively in reducing the burden women often have.

\section{Acknowledgments}

This study was coordinated by Kenya Agricultural \& Livestock Research Organisation (KALRO) under the Pre-cooked Bean Project implemented in Uganda and Kenya. The authors acknowledge county extension officers from Narok,
Bomet, Homa Bay, and Machakos in Kenya for their support in coordinating data collection. They thank all the farmers who took part in the survey.

\section{Authors' contributions}

EBN conceived and designed the study, drafted the manuscript, and coordinated the write-up. YKN reviewed the manuscript from time to time and proposed the appropriate conceptual framework. MM collected and analyzed the quantitative data and reviewed the manuscript. CO collected and analyzed the qualitative data and reviewed the work. DK supervised all stages of the study. All the authors read and approved the final manuscript.

\section{Funding}

This work was funded by the Australian Centre for International Agricultural Research (ACIAR) and the International Development Research Centre (IDRC) through Cultivate Africa's Future Fund Phase 1 in Uganda and Kenya. This paper's publication was funded by the Consultative Group for International Agricultural Research (CGIAR) Generating Evidence and New Directions for Equitable Results (GENDER) Platform. The CGIAR's Gender Platform is a new platform designed to put gender equality at the forefront of global agricultural research for development and transform how gender research is done within and beyond the CGIAR. ILRI GENDER Platform Window 1/Window 2 Grant.

\section{Availability of data and materials}

Data that support the findings of this study are available from the authors upon reasonable request.

\section{Ethics approval and consent to participate}

This project was carried out in Kenya and Uganda from 16/09/2014 to 09/09/2017. The Uganda Council for Science and Technology (UNCST) approved the project and the registration number SS 3607.

\section{Consent for publication}

This manuscript has not been published or submitted for publication elsewhere.

\section{Competing interests}

The authors declare that they have no competing interests.

\section{Author details}

${ }^{1}$ International Center for Tropical Agriculture, Nairobi, Kenya. ${ }^{2}$ Consultant, International Center for Tropical Agriculture, Nairobi, Kenya. ${ }^{3}$ University of Eastern Finland, Joensuu, Finland. ${ }^{4}$ Kenya Agricultural and Livestock Research Organisation, Nairobi, Kenya.

Received: 17 July 2020 Accepted: 1 January 2021

Published online: 07 May 2021

\section{References}

1. Iwasaki Y. Leisure and meaning-making: the pursuit of a meaningful life through leisure. In: Beniwal A, Jain R, Spracklen K, editors. Global leisure and the struggle for a better world. Basingstoke: Palgrave Macmillan; 2018.

2. Drake B. Another gender gap: men spend more time in leisure activities. Washington, D.C.: Pew Research Center; 2013.

3. Grassi F, Landberg J, Huyer S. Running out of time: the reduction of women's work burden in agricultural production. Rome: Food and Agriculture Organisation of the United Nations; 2015.

4. Vickery C. The time-poor: a new look at poverty. J Human Resour. 1977;12:27. https://doi.org/10.2307/145597.

5. Blackden CM, Wodon Q, editors. Gender, time use, and poverty in subSaharan Africa. Washington, DC: World Bank; 2012.

6. World Bank, Food and Agriculture Organization of the United Nations, International Fund for Agricultural Development. Gender in agriculture sourcebook. Washington, D.C.: World Bank; 2009.

7. Mahat I. Alternative energy and women in rural Nepal. LEISA Magazine; 2005.

8. Paris TR, Chi TTN. The Impact of row seeder technology on women labor: a case study in the mekong Delta, Vietnam. Gender Technol Dev. 2005;9:157-87. https://doi.org/10.1177/097185240500900201. 
9. https://www.gsma.com/mobilefordevelopment/wp-content/uploa ds/2013/01/GSMA_mWomen_Striving_and_Surviving_Exploring_the_ Lives_of_BOP_Women.pdf. Accessed 7 Jan 2021.

10. Anaza E. Benefits derived from recreation and sport leisure that motivate participation. AFRREV IJAH Int J Art Humanities. 2017;6:51. https://doi. org/10.4314/ijah.v6i3.5.

11. Maina LW, Kimani E. Gendered patterns of unpaid care and domestic work in the urban informal settlements of Nairobi, Kenya: findings from a household care survey-2019; 2019. https://doi.org/10.21201/2019.5068.

12. Suda C. Gender disparities in the Kenyan labour market. Nordic J Afr Stud. 2002;11:301-21.

13. Wanjala BM, Were M. Gender disparities and economic growth in Kenya: a social accounting matrix approach. Feminist Econ. 2009;15:227-51. https ://doi.org/10.1080/13545700902893114.

14. Antonopoulos R, Masterson T, Zacharias A. It's about "time": why time deficits matter for poverty. Annandale-On-Hudson: Levy Economics Inst; 2012

15. Muriithi MK, Mutegi RG, Mwabu G. Counting unpaid work in Kenya: gender and age profiles of hours worked and imputed wage incomes. J Econ Ageing. 2017. https://doi.org/10.1016/j.jeoa.2017.04.004.

16. Eagly AH. Sex differences in social behavior: a social-role interpretation/ Alice H. Eagly. Hillsdale: L. Erlbaum Associates; 1987.

17. Eagly $\mathrm{AH}$, Wood W. The origins of sex differences in human behavior: evolved dispositions versus social roles. Am Psychol. 1999;54:408-23. https://doi.org/10.1037/0003-066X.54.6.408.

18. Eagly AH, Wood W, Diekman AB. Social role theory of sex differences and similarities: a current appraisal. In: Eckes T, Trautner HM, editors. The developmental social psychology of gender. Mahwah: Erlbaum; 2000. p. 123-74.

19. Langat HK. Social cultural factors influencing women's participation in food security programs among households in Bomet County, Kenya [Master's dissertation]. Nairobi, Kenya: University of Nairobi; 2016.

20. https://idl-bnc-idrc.dspacedirect.org/bitstream/handle/10625/58632/ IDL\%20-\%2058632.pdf. Accessed Jan 2021.

21. Government of Kenya. Narok county development profile 2013-2017'. Nairobi: Ministry of Devolution and Planning; 2013.

22. Alkire S, Meinzen-Dick R, Peterman A, Quisumbing A, Seymour G, Vaz A. The Women's empowerment in agriculture index. World Dev. 2013;52:7191. https://doi.org/10.1016/j.worlddev.2013.06.007.

23. https://www.ifpri.org/sites/default/files/Basic\%20Page/weai_instructio nalguide_1.pdf. Accessed 7 Jan 2021.

24. Hyder AA, Maman S, Nyoni JE, Khasiani SA, Teoh N, Premii Z, Sohani S. The pervasive triad of food security, gender inequity and women's health: exploratory research from sub-Saharan Africa. Afr Health Sci. 2005:5:328-34

25. Lusey H, San Sebastian M, Christianson M, Edin KE. Prevalence and correlates of gender inequitable norms among young, church-going women and men in Kinshasa, Democratic Republic of Congo. BMC Public Health. 2018;18:887. https://doi.org/10.1186/s12889-018-5742-9.

26. Wambua $S$, et al. Influence of productive resources on bean production in male-and female-headed households in selected bean corridors of Kenya. Agric Food Secur. 2018;7(1):85.
27. Siri B, Nchanji E, Tchouamo I. A gender analysis on the participation and choice of improved and local haricot bean (Phaseolus vulgaris L.) by farmers in Cameroon. Agric Sci. 2020;11:1199-216. https://doi.org/10.4236/ as.2020.1112079.

28. Nakazi F, Njuki J, Ugen MA, Aseete P, Katungi E, Birachi E, et al. Is bean really a women's crop? Men and women's participation in bean production in Uganda. Agric Food Secur. 2017;6:237. https://doi.org/10.1186/ s40066-017-0102-Z

29. Abera B, Berhane M, Nebiyu A, Ruelle ML, McAlvay A, Asfaw Z, et al. Diversity, use and production of farmers'varieties of common bean (Phaseolus vulgaris L., Fabaceae) in southwestern and northeastern Ethiopia. Genet Resour Crop Evol. 2020;67:339-56. https://doi.org/10.1007/s10722-01900877-4.

30. Bikketi E, Ifejika Speranza C, Bieri S, Haller T, Wiesmann U. Gendered division of labour and feminisation of responsibilities in Kenya; implications for development interventions. Gender Place Cult. 2016;23:1432-49. https://doi.org/10.1080/0966369X.2016.1204996.

31. Alesina AF, Giuliano P, Nunn N. On the origins of gender roles: women and the plough. Quart J Econ. 2013;128:469-530.

32. Gella AA, Tadele G. Gender and farming in Ethiopia: an exploration of discourses and implications for policy and research. Future Agricultures Working Paper, 84; 2012.

33. Sperling L, Loevinsohn ME. The dynamics of adoption: distribution and mortality of bean varieties among small farmers in Rwanda. Agric Syst. 1993:41:441-53. https://doi.org/10.1016/0308-521X(93)90044-3.

34. Galiè A. Governance of seed and food security through participatory plant breeding: empirical evidence and gender analysis from Syria. Nat Resour Forum. 2013;37:31-42. https://doi.org/10.1111/1477-8947.12008.

35. Owuor SO. Migrants, urban poverty and the changing nature of urbanrural linkages in Kenya. Dev Southern Afr. 2007;24:109-22. https://doi. org/10.1080/03768350601165926.

36. Geere JAL, Cortobius M, Geere JH, Hammer CC, Hunter PR. Is water carriage associated with the water carrier's health? A systematic review of quantitative and qualitative evidence. BMJ Glob Health. 2018;3:e000764 https://doi.org/10.1136/bmjgh-2018-000764.

37. Kansanga MM, Antabe R, Sano Y, Mason-Renton S, Luginaah I. A feminist political ecology of agricultural mechanization and evolving gendered on-farm labor dynamics in northern Ghana. Gender Technol Dev. 2019;23:207-33. https://doi.org/10.1080/09718524.2019.1687799.

38. Bergman Lodin J, Tegbaru A, Bullock R, Degrande A, Nkengla LW, Gaya HI. Gendered mobilities and immobilities: Women's and men's capacities for agricultural innovation in Kenya and Nigeria. Gender Place Cult. 2019;26:1759-83. https://doi.org/10.1080/0966369X.2019.1618794.

39. Bergman LJ, Tegbanu A, Bullock R, Degrande A, Nkengla LW, Gaya HI. Gendered mobilities and immobilities: Women's and men's capacities for agricultural innovation in Keny and Nigeria. Gend Place Cult. 2019. https ://doi.org/10.1080/0966369x.2019./1618792.

\section{Publisher's Note}

Springer Nature remains neutral with regard to jurisdictional claims in published maps and institutional affiliations.

\footnotetext{
Ready to submit your research? Choose BMC and benefit from:

- fast, convenient online submission

- thorough peer review by experienced researchers in your field

- rapid publication on acceptance

- support for research data, including large and complex data types

- gold Open Access which fosters wider collaboration and increased citations

- maximum visibility for your research: over 100M website views per year
}

At BMC, research is always in progress.

Learn more biomedcentral.com/submissions 